\title{
CFRP Strengthening of Beams in Reinforced Concrete Frames with Openings in Shear Zone
}

\author{
Osama A. Mohamed ${ }^{1}$, Rania M. Khattab ${ }^{2}$ \\ ${ }^{1}$ College of Engineering, Abu Dhabi University, \\ Abu Dhabi, United Arab Emirates \\ osama.mohamed@adu.ac.ae; r.nabil-adjunct@adu.ac.ae \\ ${ }^{2}$ College of Engineering, Abu Dhabi University, \\ Abu Dhabi, United Arab Emirates
}

\begin{abstract}
Openings through reinforced concrete frame beams are often necessary to accommodate utility pipes and/or ducts. Openings in flexural members may decrease their load-carrying capacity and stiffness leading to increased deflection. This paper presents the findings of a numerical study that examined the effectiveness of carbon fibre reinforced polymer (CFRP) fabric in strengthening reinforced concrete flexural members with openings. The effectiveness of different strengthening configurations in the vicinity of openings in the shear zone are evaluated by modelling nine frames and comparing the results to the $10^{\text {th }}$ (control) frame with has opening but without strengthening. The FRP fabric configurations included strengthening around the opening, inside the opening, and both around and inside the opening. In addition, for each of the configurations, the thickness of fabric layers was varied. Finite element models demonstrated that CFRP strengthening increases the ultimate load-carrying capacity and decreases deflection. However, increasing CFRP sheet thickness has little effect on the maximum load capacity.
\end{abstract}

Keywords: Flexural member, CFRP, RC Frame, Opening in shear zone, Strengthening, finite element method.

\section{Introduction}

To allow for the passage of utility ducts and pipes, it is sometimes necessary to create openings in reinforced concrete (RC) beams that are part of moment frames. Creating openings in flexural members of RC frame reduces the cross-sectional area, and when the opening is in the shear zone, the shear capacity decreases as well. If openings are created in existing beams, the stiffness, flexural and/or shear capacity may be fully or partially restored by strengthen the beam using external fibre reinforced polymer (FRP) fabrics or sheets. Ahmed et al. [1] tested four beams, one beam strengthened using $1.2 \mathrm{~mm}$ thick CFRP sheets, and three beams strengthened using $2 \mathrm{~mm}, 3 \mathrm{~mm}$, and $4 \mathrm{~mm}$ thick steel plates. The results show that increasing steel plate thickness has little effect on the maximum load capacity while CFRP sheets were more effective in increasing the load capacity of beams. Ashwin et al. [2] investigated the effect of strengthening beams using CFRP sheets on deflection and load-carrying capacity when openings are located in the shear zone. A total of thirteen concrete beams were prepared and tested under two-point loading. Three control beams didn't contain openings, four beams contained openings but without strengthening, four beams with openings and strengthened with CFRP sheets, and two beams were retrofitted with CFRP sheets. Test results indicate that the amount of decrease in strength due to web opening depended on opening shape. It was also noted that the load-carrying capacity increased due to strengthening of the openings in the shear zone with CFRP sheets. Amer et al. [3] conducted theoretical and experimental studies on 2.00 meter long beams that are $200 \times 300 \mathrm{~mm}$ in cross-section strengthened with FRP strips to enhance shear strength. The variables investigated included CFRP strip orientation (vertical and inclined) and spacing between strips. The investigators concluded that shear strengthening of concrete beams using C8 FRP strips increased the cracking load, yield load, and ultimate load by $10 \%, 71 \%$ and $77 \%$ respectively. Inclined CFRP strips increased yield and ultimate loads by $11 \%$ and 13\%, respectively, over vertical CFRP strips having the same spacing. When all faces of the beams were covered with CFRP strips, the yield and ultimate loads increased by $82 \%$ and $95 \%$ respectively. Furthermore, CFRP strips changed the failure mode from shear to flexure by increasing the shear strength, and increasing ductility by $198 \%$ on average. Waleed et al. [4] carried out experimental and numerical studies using the commercial software Abaqus to examine the influence of the size and the layout of the web openings on the load carrying-capacity and serviceability of reinforced concrete deep beams. Five full-scale simply supported 
reinforced concrete deep beams with two large web openings created in shear regions were tested up to failure. Square openings were located symmetrically relative to the midspan section either at the midpoint or at the interior boundaries of the shear span. Two different side dimensions for the square openings were considered, $200 \mathrm{~mm}$ and $230 \mathrm{~mm}$. The strength results indicate that the shear capacity of deep beams is governed by the size and location of web openings, and the reduction of in shear capacity due to web opening may be as high as $66 \%$. Nasr et al. [5] conducted a numerical study of fifty-seven beams with $200 \times 100 \mathrm{~mm}$ and $300 \times 100 \mathrm{~mm}$ openings. The centreline of the opening is located at distances of 225, 300, 350 and $400 \mathrm{~mm}$ from the near support. Six FRP sheets strengthening schemes around the opening were examined. Numerical analysis indicated that strengthening beam opening using FRP sheets significantly improves its overall rigidity and regains part of the stiffness lost due to the opening creation. Failure loads are largely affected by the strengthening scheme and are slightly affected by spacing. Tarek et al. [6] investigated the response of FRP strengthened RC beams containing large rectangular web openings in the flexure zone. Parameters studied included type of loading, opening size, and strengthening scheme. The investigators concluded that for RC beams with opening in the pure flexure zone, the ultimate capacity is not influenced by the opening if the depth of the top chord is more than or equal to the depth of the concrete stress block at ultimate state. Hence, strengthening is not required for such cases. However, in cases where the depth of the top chord is less than the depth of the concrete stress block, strengthening may be needed to restore the beam strength. The objective of this paper is to present the results of a numerical study conducted to evaluate the load-carrying capacity and deflection of a flexural member that is part of a reinforced concrete moment frame containing rectangular openings in the shear zone, and strengthened around and inside the opening using CFRP sheets.

\section{Shear Strength provided by FRP}

For a beam with openings strengthened using FRP sheet, the applied shear force is carried by the top and the bottom chords of the openings. The shear strength of each strengthened chord is computed by combining the contribution of the FRP sheet, $V_{f}$, to the contribution of concrete, $V$ c. Therefore, the nominal shear strength of the bottom chord, $\boldsymbol{V}_{\boldsymbol{n} \boldsymbol{b}}$, and the top chord , $\boldsymbol{V}_{\boldsymbol{n} \boldsymbol{t}}$, are given by Eqs (1) - (2).

$$
\begin{aligned}
& V_{n b}=V_{c b}+V_{f b} \\
& V_{n t}=V_{c t}+V_{f t}
\end{aligned}
$$

Where,

$V_{c b}, V_{c t}$ are the shear strengths provided by concrete in the bottom and the top chords, respectively.

$V_{f b}, V_{f t}$ are the shear strengths provided by FRP strengthening sheets at the bottom and the top chords, respectively.

The concrete contribution to the shear resistance in the opening chords is given by Eqs. (3)-(4), obtained from ACI 318-14 [7].

$$
\begin{aligned}
V_{n t}=\frac{1}{6} \sqrt{f_{c}^{\prime}} b_{w} d_{t} & \text { (S.I. units) } \\
V_{c b}=\frac{1}{6} \sqrt{f_{c}^{\prime}} b_{w} d_{b} & \text { (S. I. units) }
\end{aligned}
$$

Where,

$f_{c}^{\prime}$ is the cylinder compressive strength of concrete.

$b_{w}$ is the beam width.

$d_{b}, d_{t}$ are the effective depth of the bottom and the top chords, respectively.

The shear strength, $V_{f}$, provided by FRP strengthening sheets is given by Eq. (5), obtained from ACI $440.2 \mathrm{R}-17$ [8].

$$
V_{f}=\frac{A_{f} E_{f} \quad f e(\sin \sin +\cos \cos ) d_{f v}}{s_{f}} \quad \text { (S. I. units) }
$$

The parameter $\alpha$ is the angle between the principal fibre orientation and longitudinal axis of the opening chord. In this study, $\alpha=90^{\circ}$, therefore, Eq. (5) specializes to Eq. (6). 


$$
V_{f}=\frac{A_{f} E_{f} \quad f e d_{f v}}{s_{f}}
$$

Where,

$\mathrm{A}_{f v}$ is the cross -sectional area of FRP strengthening sheets and is given by Eq. (7).

$$
A_{f v}=2 n t_{f} w_{f}
$$

$d_{f v}$ is the effective depth of the FRP shear reinforcement, taken as 0.9 of the effective depth of the beam for full FRP wrapped sections, and taken also as 0.9 of the height of FRP on the side of the beam for U-wrapped sections.

$E_{f}$ is elastic modulus of FRP.

$S_{f}$ is the center- to- center spacing of FRP strips.

$t_{f}$ is the thickness of FRP.

$n$ is the number of FRP layers.

$w_{f}$ is the width of FRP strip, which equal to $S_{f}$ for continuous FRP.

$\varepsilon_{f e}$ is the effective strain in FRP, given by Eq. (8) and is a function of the ultimate strain, $\varepsilon_{f u}$.

$$
\begin{aligned}
& f e=\left\{0.004 \leq 0.75_{f u} \text {, for full FRP wrap } f u \leq 0.004 \quad \text {, for } U-\right. \\
& \text { wraps or two sides bonded }
\end{aligned}
$$

An additional reduction factor, $\psi_{f}$, given by Eq. (9) is applied to the FRP contribution to shear strength.

$$
f=\{0.95, \text { for full FRP wrap } 0.85 \quad \text {, for } U-\text { wraps or two sides bonded }
$$

Code-based procedure for estimating the effective bond length of FRP strengthening sheets was investigated by the authors [9].

\section{Description of Reinforced Concrete Frames}

In this study, numerical analysis was conducted on nine reinforced concrete, the span of each frame is $5700 \mathrm{~mm}$, in addition to one control frame (Frame 0). Openings dimensions are $600 \times 300 \mathrm{~mm}$ created at a distance of $850 \mathrm{~mm}$ from edge of the opening to the edge support column, as shown in Figure 1. The beam of the RC frame is reinforced with three 16mm-diameter bars in the compression zone, two 12-mm-diameter bars in tension zone, and 10-mm-diameter steel stirrups spaced at $200 \mathrm{~mm}$. The frame columns are reinforced with six 16-mm-diameter bars as longitudinal reinforcement and 10$\mathrm{mm}$-diameter steel stirrups spaced at $200 \mathrm{~mm}$. Figure 1 illustrates the dimensions, opening details, and reinforcement details of the frame. The first set of three frames (frames 1 to 3) was strengthened with CFRP sheets around the opening, with thicknesses of 1, 2, and $2.5 \mathrm{~mm}$, respectively. The second set of three Frames (frames 4 to 6) are strengthened with CFRP sheets inside the opening, with the same three FRP thicknesses as set 1. The third set of three frames (frames 7 to 9) are strengthened with CFRP sheets around and inside the opening, with the same thicknesses as sets 1 and 2. Table 1 shows the designations and FRP strengthening details.

\section{Finite Element Model}

The general-purpose finite element software ABAQUS [10] was used to simulate the structural response of the concrete frames with openings with/without FRP strengthening sheets. Eight-node brick element with reduced integration, capable of simulating nonlinearity was used to model the concrete. It is also capable of simulating cracking and crushing in tension and compression regions. The concrete material model implemented in Abaqus is a continuum, plasticity-based model that considers the two dominant concrete failure modes, namely, concrete tensile cracking and concrete compressive crushing. Skin Reinforcement was used to model the FRP strips, assumed to be perfectly bonded externally to the frame beam. Figure 2 shows the concrete frame and reinforcing steel for the control frame (Frame 0). The model was discretized into finite elements by meshing before applying the loading system. Either beam elements or truss elements can be used to simulate steel bars. In this study, a uniaxial tension-compression element with three translational degrees of freedom at each node was 
used to simulate reinforcing steel bars. Reinforcing steel bars are fully embedded in concrete, therefore, their degrees of freedom are not independent of the degrees of freedom of concrete leading to the assumption of perfect bond. This assumption ignores the development of shear stresses at the interface of materials, as well as the slip between the reinforcing elements and surrounding materials. CFRP sheets were modelled using linear- elastic and orthotropic membrane elements. Membrane elements are used to represent thin surfaces in space that offer strength in the plane of the surface but have no bending stiffness. Two point loads were applied at one-third points of the span between the supporting columns. Simple support condition was created at the bases of the columns of the concrete frame. Table 2 shows details of the material properties for concrete, steel and CFRP.

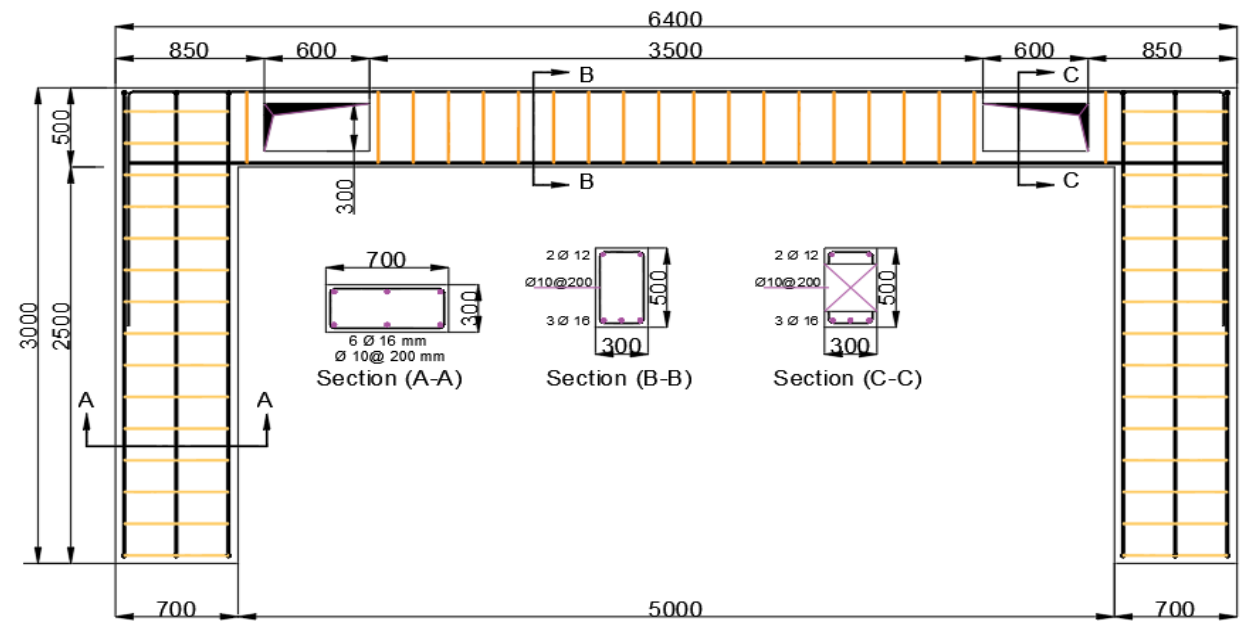

Fig. 1: Longitude profile of reinforced concrete Frame (Frame 0)

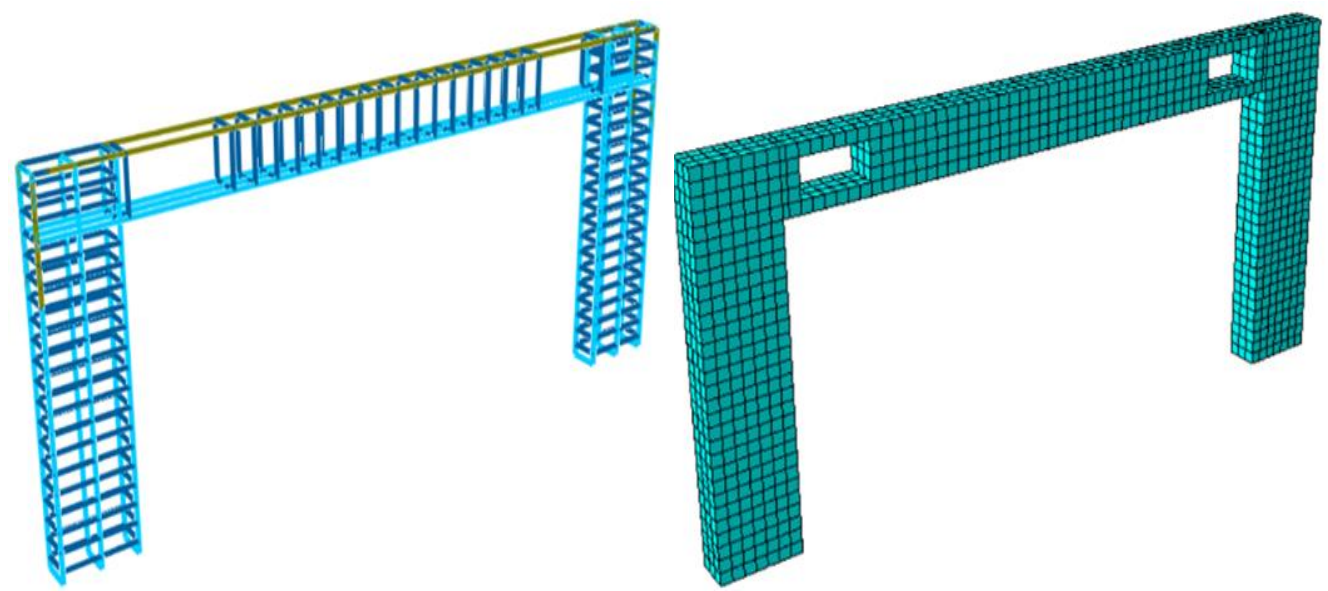

Fig. 2: Assembly model developed in ABAQUS for Frame-0

Table 1: Designation and Details of the Modelled Beam.

\begin{tabular}{|l|l|l|}
\hline $\begin{array}{l}\text { Designation } \\
\text { on Frame }\end{array}$ & Type of Strengthened & Thickness (mm) \\
\hline Frame 0 & Control Frame & \\
\hline
\end{tabular}




\begin{tabular}{|c|c|c|}
\hline Frame 1 & \multirow{3}{*}{$\begin{array}{l}\text { CFRP wrapping } \\
\text { around the opening }\end{array}$} & 1.0 \\
\hline Frame 2 & & 2.0 \\
\hline Frame 3 & & 3.0 \\
\hline Frame 4 & \multirow{3}{*}{$\begin{array}{l}\text { CFRP wrapping } \\
\text { inside the opening }\end{array}$} & 1.0 \\
\hline Frame 5 & & 2.0 \\
\hline Frame 6 & & 3.0 \\
\hline Frame 7 & \multirow{3}{*}{$\begin{array}{l}\text { CFRP wrapping } \\
\text { around and } \\
\text { inside the } \\
\text { opening }\end{array}$} & 1.0 \\
\hline Frame 8 & & 2.0 \\
\hline Frame 9 & & 3.0 \\
\hline
\end{tabular}

Table 2: Material properties of concrete, steel, and CFRP

\begin{tabular}{|l|l|l|}
\hline Material & Description & Value \\
\hline Concrete & Density, $\mathrm{kg} / \mathrm{m}^{3}$ & 2500 \\
& Elastic modulus, GPa & 28.3 \\
& Poisson's ratio & 0.2 \\
& Comp. strength (cylinder) of concrete, MPa & 30 \\
\hline Steel & Density, kg/m ${ }^{3}$ & 7850 \\
& Poisson's ratio & 0.3 \\
& Elastic modulus, GPa & 20600 \\
& Yield strengths of Steel bars, MPa & 379 \\
& Ultimate strengths of Steel bars, MPa & 581 \\
\hline CFRP & Young modulus, $\mathrm{E}_{11}, \mathrm{GPa}$ & 228 \\
& Young modulus, $\mathrm{E}_{22}=\mathrm{E}_{33}, \mathrm{GPa}$ & 9.65 \\
& Poisson's ratios 223 $_{23}$ & 0.45 \\
& Poisson's ratios $\left\{{ }_{12}=\{13\right.$ & 0.30 \\
& Shear modulus, $\mathrm{G}_{23}, \mathrm{GPa}$ & 3.4 \\
& Shear modulus, $\mathrm{G}_{12}=\mathrm{G}_{13}, \mathrm{GPa}$ & 5.4 \\
& Tensile Strain & 0.017 \\
\hline
\end{tabular}

\section{Results and discussion}

This section discusses the beam deflection, maximum load-carrying capacity, and the characteristics of the loaddeflection curve of the concrete frames strengthened with CFRP sheets.

\subsection{Deflection}

The mid-span deflection of the beam with opening strengthened using CFRP sheets in each of the nine concrete frames was lower than the deflection at the mid span of the control frame. The control frame (frame 0) has beam opening that was not strengthened with CFRP. The reduction in deflection ranged from $10 \%$ to 35\%, as shown in Table 3 . The strengthening process helped the beam in the concrete frame to restore part of its stiffness that was lost due to the existence of openings. The amount of stiffness recovery depends on the strengthening scheme and thickness of CFRP sheets.

Table 3: Deflection at mid span of frame's beam 


\begin{tabular}{|c|c|c|}
\hline Designation on Frame & $\begin{array}{c}\text { Deflection at mid span in } \\
(\mathrm{mm})\end{array}$ & Decrease in deflection in \% \\
\hline Frame 0 & 99.98 & $13 \%$ \\
\hline Frame 1 & 87.44 & $10 \%$ \\
\hline Frame 2 & 89.90 & $15 \%$ \\
\hline Frame 3 & 84.82 & $33 \%$ \\
\hline Frame 4 & 66.64 & $32 \%$ \\
\hline Frame 5 & 68.16 & $29 \%$ \\
\hline Frame 6 & 70.84 & $26 \%$ \\
\hline Frame 7 & 74.38 & $35 \%$ \\
\hline Frame 8 & 64.81 & $29 \%$ \\
\hline Frame 9 & 71.45 & \\
\hline
\end{tabular}

\subsection{Effect of FRP strengthening on load-carrying capacity}

The ultimate load at failure and mode of failure for each of the frames are shown in Table 4. The highest increase in load-carrying capacity in the first set of three frames $(1,2$, and 3) where FRP strengthening was applied around the opening, occurred in frame 3 and amounts to 27\%. For second schema (CFRP inside the opening), frame 6 exhibited the highest increase in load-carrying capacity of $18 \%$. The increase in load-carrying capacity for frames 7,8 , and 9 strengthened using the third schema (FRP inside and around the opening), was higher than the first and second schema of FRP strengthening regardless of thickness of FRP. The highest overall increase in load-carrying capacity of 38\% was exhibited by frame 9 . Therefore, applying CFRP sheets around and inside the opening is the most effective method of strengthening openings in the shear zone. However, for all of the strengthening schema, failure of RC frames was accompanied by shear cracking at edge of the opening.

Table 4: Ultimate Load Carrying Capacity of RC Frames

\begin{tabular}{|l|c|c|c|}
\hline $\begin{array}{c}\text { Designation of } \\
\text { Frame }\end{array}$ & $\begin{array}{c}\text { Ultimate Failure Load } \\
(\mathrm{kN})\end{array}$ & $\begin{array}{c}\text { Increase in Load-carrying } \\
\text { Capacity }\end{array}$ & Failure Mode \\
\hline Frame 0 & 63.42 & & $\begin{array}{c}\text { Flexural shear } \\
\text { Failure }\end{array}$ \\
\hline Frame 1 & 76.07 & $20 \%$ & Shear at opening \\
\hline Frame 2 & 79.70 & $26 \%$ & Shear at opening \\
\hline Frame 3 & 80.39 & $27 \%$ & Shear at opening \\
\hline Frame 4 & 71.95 & $13 \%$ & Shear at opening \\
\hline Frame 5 & 73.15 & $15 \%$ & Shear at opening \\
\hline Frame 6 & 75.04 & $29 \%$ & Shear at opening \\
\hline Frame 7 & 81.95 & $36 \%$ & Shear at opening \\
\hline Frame 8 & 85.98 & $38 \%$ & Shear at opening \\
\hline Frame 9 & 87.22 & & Shear at opening \\
\hline
\end{tabular}

\subsection{Ultimate Load}

Figure. 3 compares the ultimate load of various concrete frames to the reference frame. For the same thickness of CFRP, the third schema (CFRP around the opening and inside the opening) produces the highest ultimate load. All CFRP strengthening schema produced higher ultimate load compared to the control frame. 


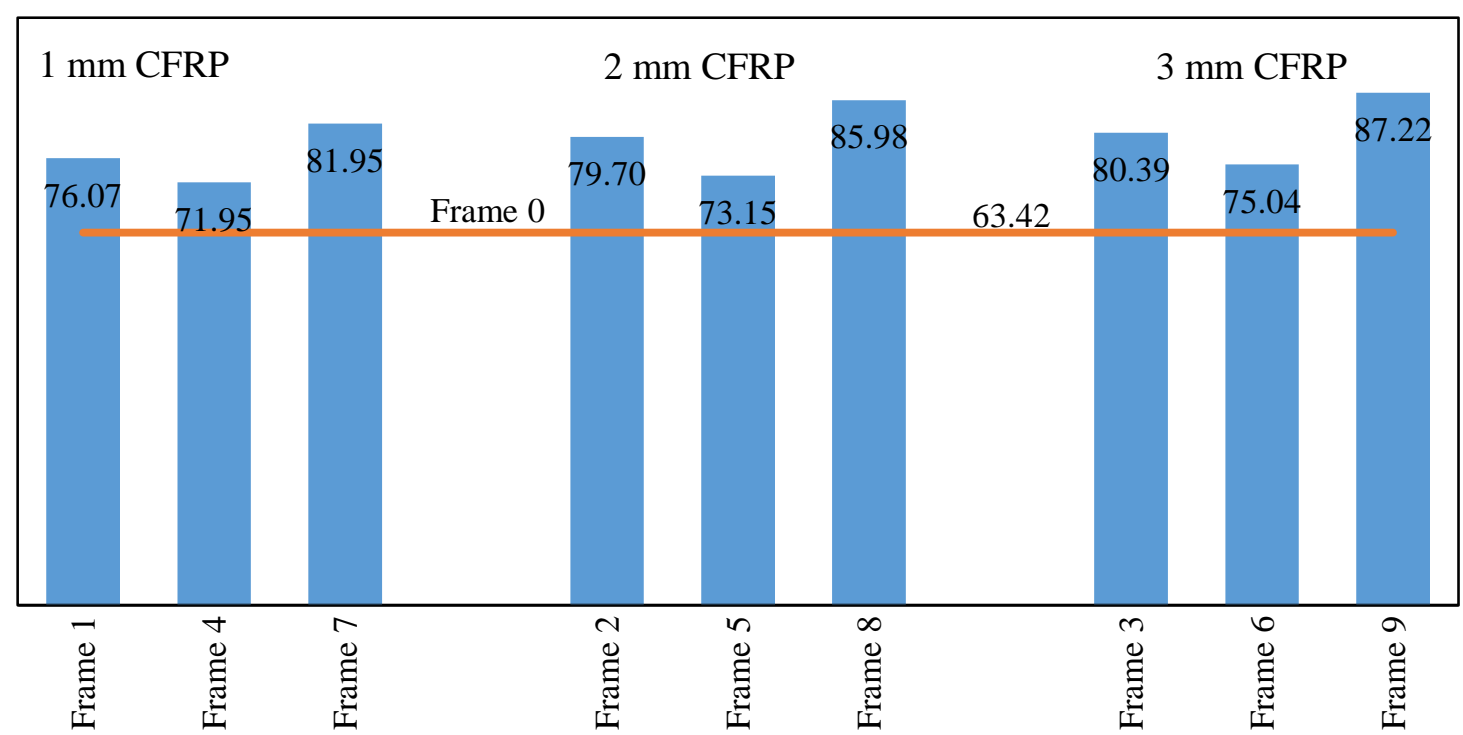

Fig. 3: Ultimate load of various RC frames.

\subsection{Load-Deflection Behaviour of RC frames}

Figure 4 shows the load -deflection curves of the reinforced concrete frames analysed in this study. Figures 4(a), (b), and (c) show the load-deflection curves for RC frames strengthened with CFRP with thicknesses of $1 \mathrm{~mm}, 2 \mathrm{~mm}$, and $3 \mathrm{~mm}$, respectively. The control frame (Frame 0) sustained a maximum load of $63.42 \mathrm{kN}$ with a corresponding deflection of 99.98 $\mathrm{mm}$. The beam in frame 9 strengthened with $3 \mathrm{~mm}$ thick CFRP sheets around and inside the opening, sustained the maximum load of $87.22 \mathrm{kN}$ with a corresponding deflection of $71.45 \mathrm{~mm}$. This represents an increase of $38 \%$ in load-carrying capacity and a reduction of $29 \%$ in deflection, compared to the control frame. Figure 4 also demonstrates that the increase in loadcarrying capacity of the FRP strengthened frames is accompanied with reduction in ductility.

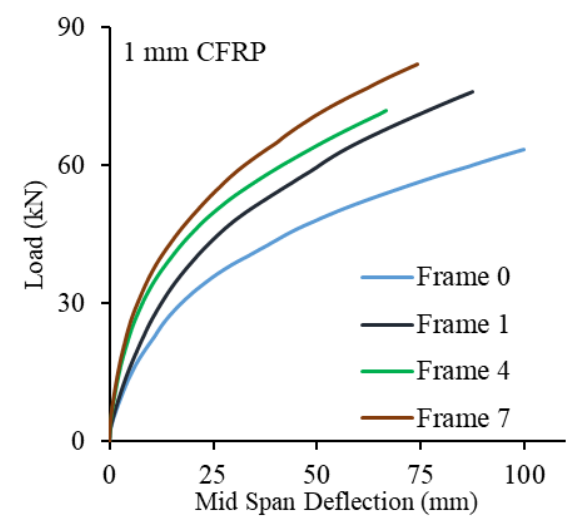

(a) $1 \mathrm{~mm}$ thick CFRP

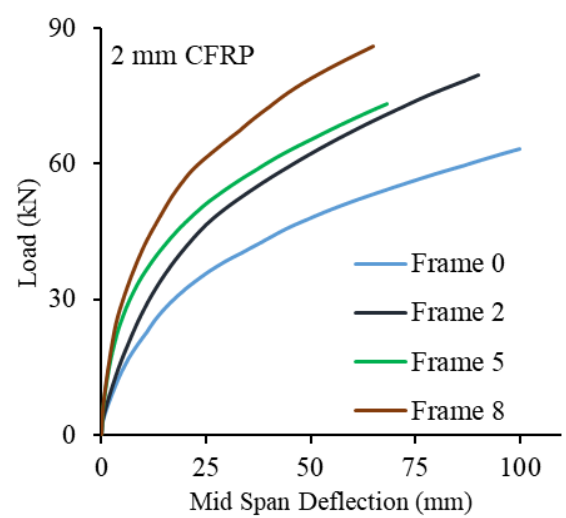

(b) $2 \mathrm{~mm}$ thick CFRP

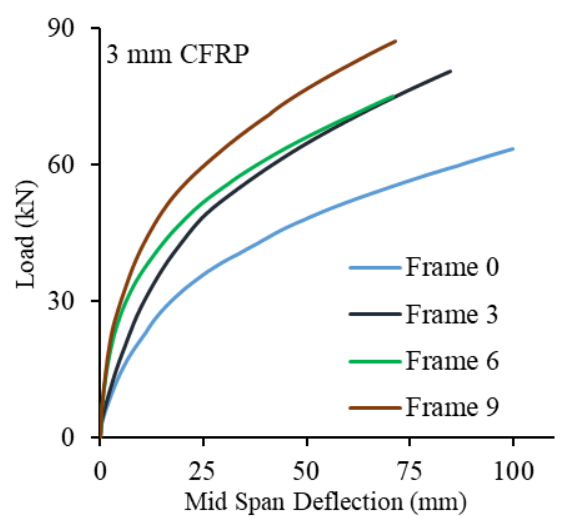

(c) $3 \mathrm{~mm}$ thick CFRP

Fig. 4: Load- Deflection Curve for strengthen RC frames.

\section{Conclusions}

Numerical analysis was conducted using nonlinear finite element method to evaluate the load-carrying capacity of nine reinforced concrete frames with opening $s$ in the shear zone that are strengthened using CFRP laminates around the opening, inside the opening, and both around and inside the opening. The following conclusions can be drawn: 
- Strengthening beam openings located in the shear zone using CFRP sheets increases frame rigidity and decreases the deflection at failure.

- Use of CFRP sheets or laminates for strengthening openings in beams of reinforced concrete frames increases the ultimate load-carrying capacity significantly.

- The failure load depends on the strengthening schema and thickness of FRP laminates. Strengthening beam opening with CFRP around and inside the opening offers the best results in restoring the load-carrying capacity affected by openings in the shear zone.

\section{References}

[1] A. Ahmed A, S. Naganathan, K. Nasharuddin1, and M.M. Fayyadh," Repair effectiveness of CFRP and steel plates in RC beams with web opening: effect of plate thickness" International Journal of Civil Engineering, June 2015, vol. 13, No. 2. http://ijce.iust.ac.ir/article-1-962-en.pdf

[2] Ashwin.C.S, Shivakumaraswamy B. and AIT , "Experimental Investigation on the Study of Rectangular RC Beams with Opening Strengthened with CFRP", International Journal of Engineering Science and Computing, August 2017, vol. 7, Issue No.8.

[3] Amer M. Ibrahim, Ahmed Abdullah Mansor and Muthafer Hameed, "Structural Behavior of Strengthened RC Beams in Shear using CFRP Strips", The Open Civil Engineering Journal, 2017, vol.11, 205-215. http://dx.doi.org/10.2174/1874149501711010205

[4] Waleed A. Jasim, Abbas A. Allawi, and Nazar Kamil Ali Oukaili” Effect of Size and Location of Square Web Openings on the Entire Behavior of Reinforced Concrete Deep Beams", Civil Engineering Journal, Jan. 2019, vol. 5, No. 1, ,209226. http://dx.doi.org/10.28991/cej-2019-03091239

[5] Nasr Z. Hassan, Alaa G. Sherif, and Amal H. Zamarawy, "Finite element analysis of reinforced concrete beams with opening strengthened using FRP”, Ain Shams Engineering Journal.,2015, Production and hosting by Elsevier, vol.8,531-537. https://doi.org/10.1016/j.asej.2015.10.011

[6] Tarek Almusallam, Yousef Al-Salloum, Hussein Elsanadedy, Abdulhafiz Alshenawy and Rizwan Iqbal,” Behavior of FRP-Strengthened RC Beams with Large Rectangular Web Openings in Flexure Zones: Experimental and Numerical Study" International Journal of Concrete Structures and Materials,2018,12: 47. https://doi.org/10.1186/s40069-018$\underline{0272-5}$

[7] American Concrete Institute (ACI 318), Building code requirements for structural concrete (ACI 318-14), Farmington Hills, Mich.,2014

[8] ACI committee 440.Guide for the design and construction of externally bonded FRP systems for strengthening concrete structures, (ACI 440 2R-17), ACI committee 440, Farmington Hills, Michigan, USA. 2017

[9] Osama A. M. and R. Khattab. "Bond-Slip Modelling of FRP Sheets Externally Bonded to Concrete Beam", Elsevier ,Procedia Engineering , 2016, 161,833-838, https://doi.org/10.1016/j.proeng.2016.08.723

[10] ABAQUS. ABAQUS/standard version 6.10 user's manuals, Volume I-III, Hibbitt, Karlsson, and Sorenson, Inc., Pawtucket, RI. 2010 